\title{
ESTUDO BIOMECÂNICO DE OSSOS DE RATAS ALIMENTADAS COM DIETA HIPERLIPÍDICA
}

Gabriela Rezende Yanagihara, Faculdade de Medicina de Ribeirão Preto/USP, gyanagihara@ usp.br Roberta Carminati Shimano, Faculdade de Medicina de Ribeirão Preto/USP, roberta_cshimano@ hotmail.com Ana Paula Macedo, Faculdade de Medicina de Ribeirão Preto/USP, anapaula@forp.usp.br

João Manuel R. S. Tavares, Faculdade de Engenharia da Universidade do Porto, tavares@fe.up.pt Antônio Carlos Shimano, Faculdade de Medicina de Ribeirão Preto/USP, ashimano@fmrp.usp.br

Resumo. O objetivo deste estudo foi avaliar os efeitos da alimentação hiperlipídica sobre o tecido ósseo de ratas. Cinquenta e duas ratas Wistar, pós-desmame, foram divididas em duas fases experimentais: estudo com ratas em crescimento $(n=20)$ e estudo com ratas ovariectomizadas $(n=32)$. Na primeira fase, as ratas foram divididas em 2 grupos: ração padrão (SD) e ração hiperlipídica (HFD), tendo duração de 5 semanas. Na segunda fase, as ratas foram divididas igualmente em 4 grupos: ração padrão e cirurgia simulada (SD-SH); ração padrão e ovariectomia (SD-OVX); ração hiperlipídica e cirurgia simulada (HFD-SH); ração hiperlipídica e ovariectomia (HFD-OVX). $O$ período total do experimento foi de 18 semanas, sendo que na quinta semana foi realizado o procedimento cirúrgico. Após eutanásia os ossos foram retirados. Os fêmures foram analisados por expressão gênica dos genes PPAR- $\gamma$, Runx2, RANKL e Catepsina-K e as tíbias foram analisadas por microtomografia computadorizada, densitometria óssea e ensaios mecânicos. Na fase de crescimento, a dieta hiperlipídica promoveu aumento da expressão de PPAR- $\gamma$ e DMO, e não alterou dados microestruturais e mecânicos. Na fase de castração, foi possível observar que a dieta hiperlipídica causou aumento da expressão de PPAR- $\gamma$ e diminuição da expressão de Runx-2. Além disso, a dieta promoveu diminuição da DMO e espessura trabecular, embora não tenha modificado a resistência mecânica. Concluiu-se com o estudo que, durante o crescimento, a dieta hiperlipídica não causou alterações significantes aos ossos, mas após deficiência estrogênica foi capaz de exercer efeitos deletérios ao esqueleto.

Palavras chave: Osso. Dieta Hiperlipídica. Adiposidade. Osteoporose

\section{INTRODUÇÃO}

O papel da gordura na saúde óssea é um assunto que tem ganhado no meio científico, uma vez que se observa uma mudança nos hábitos alimentares, com aumento do consumo de alimentos ultra processados, ricos em gordura e de alto teor calórico (Kafeshani et al., 2015; Kar e Khandelwal, 2015; Bloomfield et al., 2016). Essa mudança no padrão alimentar vem acompanhada de um alto índice de obesidade precoce (Sahoo et al., 2015), gerando grandes impactos clínicos e financeiros aos sistemas nacionais de saúde (Pinheiro et al., 2009). Embora seja uma condição influenciada por fatores genéticos e hereditários, na maioria das vezes a obesidade ocorre por um desequilíbrio do consumo versus gasto de energia, devido a fatores modificáveis, como estilo de vida sedentário e uma dieta inadequada (Ghanizadeh $e t$ al., 2014).

Apesar de ser apontada como um fator de risco para muitas doenças crônicas (Rendina-Ruedy et al., 2016), a obesidade, por muito tempo, foi considerada favorável para os ossos (Lim et al., 2004; Silva et al., 2007). Os efeitos alegadamente benéficos baseiam-se, principalmente, em uma já bem estabelecida correlação entre o peso corporal e a densidade mineral óssea (DMO)(Paula e Rosen, 2010), através do aumento da sobrecarga mecânica (Silva et al., 2007). No entanto, alguns estudos mais recentes mostram resultados controversos, desde a afirmativa de que essa correlação é inexistente (Tintut et al., 2002; Looker et al., 2007), até uma correlação negativa (Matkovic et al., 1994; Hsu et al., 2006; Zhao et al., 2008). A atual teoria mundial é de que a obesidade pode prejudicar os ossos e muitas vezes acelerar o processo de perda óssea relativos à idade. Contudo, apesar de todos os avanços científicos no campo, ainda há relatos conflitantes na literatura sobre a relação entre dieta rica em gordura e o tecido ósseo porque os efeitos desta dieta ainda não foram totalmente esclarecidos. Isso porque a idade e a maturação esquelética e hormonal são fatores que influenciam diretamente no metabolismo ósseo. Uma vez que o processo de aquisição/manutenção óssea se difere nos diferentes estágios da vida, não se pode esperar que os efeitos da gordura sobre os ossos sejam os mesmos na infância e no envelhecimento. Deste modo, estudos da relação gordura versus osso sobre diferentes fases da maturação esquelética são necessários.

\section{MATERIAIS E MÉTODOS}

Este trabalho teve aprovação da Comissão de Ética em Experimentação Animal da FMRP/USP (188/2013). Para esse estudo, foram utilizadas 52 ratas wistar, com 3 semanas de vida. O estudo foi dividido em duas fases, sendo na Fase $1(n=20)$ estudadas as ratas durante o crescimento e na Fase $2(n=32)$ estudadas ratas após ovariectomia.

Os animais da Fase 1 foram divididos igualmente em 2 grupos: alimentados com dieta padrão (SD) ou com dieta hiperlipídica (HFD) durante o período experimental de 5 semanas. Os animais da Fase 2 foram divididos igualmente em 
4 grupos experimentais: dieta padrão - sham (SD-SH), dieta padrão - ovariectomia (SD-OVX), dieta hiperlipidica sham (HFD-SH) e dieta hiperlipídica - ovariectomia (HFD-OVX). Nessa fase do experimento, as ratas foram alimentadas com a ração experimental referente a cada grupo durante 18 semanas. $\mathrm{Na} 5^{\mathrm{a}}$ semana de experimento foi realizado o procedimento cirúrgico de ovariectomia ou cirurgia simualada (sham).

\subsection{Alimentação}

A ração padrão para ratos (SD) foi a AIN-93 (Reeves et al., 1993) e a ração hiperlipídica foi a AIN-93 modificada de modo a conter $60 \%$ da energia na forma de gordura proveniente de gordura animal.

\subsection{Procedimentos cirúrgicos}

Os procedimentos cirúrgicos foram realizados apenas nos grupos experimentais da Fase 2. Para a retirada dos ovários as ratas foram anestesidas com injeção intramuscular de ketamina e xilazina e após constatação dos efeitos anestésicos foram realizadas a tricotomia, assepsia e antissepsia da região dorsal do animal. Foi realizada insição dorsolateral na pele e incisão linear na musculatura para localização e exposição do ovário. O ovário foi retirado após ligadura da trompa uterina que, posteriormente, foi novamente realojada na cavidade abdmoninal. As camadas muscular e subcutânea foram suturadas e o mesmo procedimento foi realizado no lado contralateral. As ratas destinadas aos grupos SH passaram pelos mesmos procedimentos, exceto a ligadura da trompa uterina e retirada do ovário. Após o procedimento cirúrugico foi realizada analgesia por 5 dias com brupernorfina $(0,03 \mathrm{mg} / \mathrm{kg})$ (Macedo et al., 2016).

\subsection{Controle de massa}

Todos os animais passaram por controle semanal de massa corpórea do início ao fim do experimento.

\subsection{Eutanásia e coleta de materiais}

A eutanásia dos animais após 5 semanas de experimento (Fase 1) ou após 18 semanas de experimento (Fase 2) seguiu o mesmo protocolo, sendo realizada por anestesia com doses letais de ketamina e xilazina. Imediatamente após a morte, foram retirados os ossos fêmures (destinados à análise de expressão gênica), tíbias direitas (direcionadas para Microtomografia computadorizada) e tíbias esquerdas (direcionadas para densitometria e análise mecânica).

\subsection{Análises}

\subsubsection{Análise de Expressão Gênica}

Para analisar a expressão gênica, o RNA foi extraído por meio de um kit de extração de RNA (Promega®, São Paulo, Brasil) e quantificado por espectrofotometria de absorção (Eppendorf®, Hamburg, Alemanha). O cDNA foi sintetizado a partir do RNA por meio de um kit de transcrição reversa de alta capacidade (Applied Biosystems, EUA). Foi realizado sequenciamento para os genes Proliferador de Peroxissoma Gama (PPAR- $\gamma$ ), Fator de Transcrição Relacionado ao Runt 2 (Runx-2), Ligante do Receptor do Ativador do Fator nuclear Kappa B (RANKL), Catepsina-K e o gene referência foi o $\beta$-actina. A medida quantitativa da expressão do mRNA foi feita por transcriptase reversa seguida de reação em cadeia da polimerase (RT-PCR) em tempo real, por meio do sistema Taqman®RT-PCR (Life Technologies, São Paulo, Brasil). A expressão relativa de cada gene foi calculada baseando-se no threshold cycle (Ct). Os resultados foram analisados de acordo com o cálculo de $2^{-\Delta \Delta \mathrm{Ct}}$, cujo resultado representa a expressão relativa de mRNA em ordens arbitrárias (Livak e Schmittgen, 2001), sendo:

$$
\begin{aligned}
& \Delta C t=\text { Ctgene }- \text { Ctgene alvo } \\
& \Delta \Delta C t=\Delta \text { Ctgrupo }-\Delta \text { Ctcontrole }
\end{aligned}
$$

\subsubsection{Microtomografia Computadorizada}

A análise microtomográfica foi realizada em um sistema $\mu$-CT de alta resolução (SkyScan Bruker®, Kontich, Bélgica). Cinco ossos de cada grupo foram escaneados e a reconstrução das imagens obtidas após escaneamento foram feitas por meio do software NRecon ${ }^{\circledR}$ (Bruker ${ }^{\circledR}$, Kontich, Bélgica). A região de interesse delineada foi a metáfise proximal da tíbia, que contém principalmente osso trabecular. A reconstrução foi selecionada manualmente, começando imediatamente após a placa de crescimento proximal por uma extensão de 3,0mm. O osso trabecular foi isolado do cortical por meio de segmentação manual. O software CTAn ${ }^{\circledR}$ (versão 1.13.11.0, Bruker, Kontich, Bélgica) foi utilizado para determinar o nível de limiar ideal de binarização dos histogramas da imagem. Os dados quantificados da 
arquitetura trabecular foram a espessura trabecular (Tb.Th), o número de trabéculas (Tb.N) e separação trabecular (Tb.Sp). As medidas morfométricas ósseas e a nomenclatura estão de acordo com as recomendações da American Society of Bone and Mineral Research (Bouxsein et al., 2010).

\subsubsection{Análise de Densitometria Óssea}

A densidade mineral óssea (DMO) foi aferida por meio de Densitometria de Absorciometria de Raio-x de Dupla Energia (DXA). As tíbias foram alinhadas e escaneadas com a face anterior voltada para cima. As imagens adquiridas foram analisadas na região de interesse (ROI), sendo padronizada na região proximal da tíbia, imediamente abaixo da cartilagem de crescimento. O ROI teve área padrão de $0,09 \mathrm{~cm}^{2}$.

\subsubsection{Análise Mecânica}

As propriedades mecânicas de força máxima e rigidez relativa foram avaliadas por meio de ensaios mecânicos de baixa velocidade. Foi utilizada uma Máquina Universal de Ensaios DL10000 (EMIC®, São José dos Pinhais, Brasil). As tíbias foram posicionadas em um suporte de 2 apoios com $25 \mathrm{~mm}$ de distância entre eles. O ensaio realizado foi o de flexão em 3 pontos, com aplicação da carga na velocidade de 1,0 mm/min no sentido póstero-anterior da tíbia. Uma précarga de $5 \mathrm{~N}$ e um tempo de acomodação de 30 segundos foram adotados.

\subsubsection{Estatística}

A estatística foi realizada no programa SPSS versão 20.1. Para os resultados da Fase 1, a comparação foi feita grupo a grupo com o teste T-Student ou teste Mann-Whitney. Os dados de FSH da Fase 2 também foram comparados entre dois grupos, sendo utilizado o teste Mann-Whitney. O peso corporal até a $5^{\mathrm{a}}$ semana de experimento, comparado pelo teste de Kruskal-Wallis com pós-teste de Dunn. Os demais dados da Fase 2, foram avaliados conforme a influência das variáveis (cirurgia e dieta) sobre os fatores fixos. Foi utilizado o teste de modelos lineares generalizados, com teste complementar de Bonferroni. Foi adotado nível de significância de 5\% ( $\leq \leq 0,05)$.

\section{RESULTADOS}

\subsection{Fase 1}

A massa corpórea dos animais da fase 1 foram similares entre os grupos no início do experimento $(\mathrm{p}=0,257)$, bem como após a primeira semana $(\mathrm{p}=0,185)$. Entretanto, após a $2^{\mathrm{a}}$ semana, o grupo HFD apresentou maior massa corporal do que o grupo SD ( $\mathrm{p}=0,004)$. Após a $3^{\mathrm{a}}$ semana, a massa corporal estava novamente igual entre os grupos ( $\left.\mathrm{p}=0,380\right)$. Após a $4^{\mathrm{a}}$ semana, o grupo HFD apresentou, novamente, maior massa corporal comparado ao grupo SD ( $\mathrm{p}=0,022$ ). Por fim, ao final do experimento, o grupo HFD apresentou maior massa corporal comparado ao grupo SD ( $\mathrm{p}=0,022)$.

A expressão relativa do gene PPAR- $\gamma$ foi estatisticamente maior no grupo HFD comparado ao grupo SD ( $\mathrm{p}=0,028)$. No entanto, não houve diferenças estatisticamente significantes entre os grupos para os genes Runx-2 ( $\mathrm{p}=0,952)$, RANKL $(\mathrm{p}=0,505)$ e Catepsina- K $(\mathrm{p}=0,987)$.

Não foram observadas diferenças estatísticas entre os grupos quanto à espessura trabecular $(\mathrm{p}=0,802)$, ao número de trabéculas $(\mathrm{p}=0,374)$ e separação trabecular $(\mathrm{p}=0,360)$.

A DMO do grupo HFD foi estatisticamente maior do que o grupo SD ( $\mathrm{p}=0,020)$, no entanto, não foram observadas diferenças estatisticamente significantes entre os grupos para força máxima $(p=0,348)$ ou rigidez relativa $(p=0,680)$.

\subsection{Fase 2}

A massa corporal dos animais da fase 2 foram estatisticamente iguais do início do experimento até a $5^{\mathrm{a}}$ semana ( $p>0,05)$, quando foi realizado o procedimento cirúrgico. Após a cirurgia, a OVX teve influencia positiva na massa corporal na $10^{\mathrm{a}}$ semana $(\mathrm{p}=0,019)$ e ao final do experimento $(\mathrm{p}=0,030)$. A dieta hiperlipídica influenciou positivamente na massa corpórea em todas as semanas após o procedimento cirúrgico $(\mathrm{p}<0,05)$.

A cirurgia OVX $(\mathrm{p}=0,005)$ causou diminuição na expressão relativa de PPAR- $\gamma$, enquanto que a dieta hiperlipídica $(\mathrm{p}=0,048)$ causou aumento do mesmo. A interação cirurgia*dieta não foi estatisticamente significante $(\mathrm{p}=0,076)$. A cirurgia não influenciou na expressão de Runx-2 ( $\mathrm{p}=0,835)$, mas a dieta hiperlipídica resultou em menor expressão desse gene $(\mathrm{p}=0,033)$. A interação cirurgia*dieta também foi influente $(\mathrm{p}=0,049)$, mostrando que o grupo HFD-SH teve valores estatisticamente menores que os grupos HFD-OVX ( $\mathrm{p}>0,001)$, SD-OVX ( $\mathrm{p}<0,001)$. A expressão de RANKL não foi influenciada pela cirurgia $(\mathrm{p}=0,087)$, pela dieta $(\mathrm{p}=0,233)$ nem pela interação cirurga*dieta $(\mathrm{p}=0,178)$. A cirurgia OVX ( $<<0,001)$ resultou em maior expressão de CTPS-K, mas a dieta $(\mathrm{p}=0,615)$, bem como a interação cirurgia*dieta $(\mathrm{p}=0,783)$ não foram influentes na expressão desse gene. 
Foi possível observar que a cirurgia OVX resultou em maior espessura trabecular $(\mathrm{p}=0,008)$ menor número de trabéculas $(\mathrm{p}<0,001)$ e menor separação trabecular $(\mathrm{p}<0,001)$, demonstrando uma piora significativa na qualidade óssea. A dieta hiperlipídica resultou em menor espessura trabecular $(\mathrm{p}=0,029)$, também indicando piora na qualidade microestrutural.

A cirurgia OVX $(p<0,001)$ e a dieta hiperlipídica $(p=0,009)$ resultaram em menor DMO tíbia, mas a interação cirurgia*dieta não foi estatisticamente significante $(p>0,05)$. A cirurgia $(p=0,442)$, a dieta $(p=0,519)$ e a interação cirurgia*dieta $(p=0,394)$ não foram estatisticamente significantes para a propriedade de força máxima. Da mesma forma, a cirurgia $(\mathrm{p}=0,615)$, a dieta $(\mathrm{P}=0,306)$ e a interação cirurgia*dieta $(\mathrm{p}=0,730)$ também não foram significativas para rigidez relativa (Fig 1$)$.

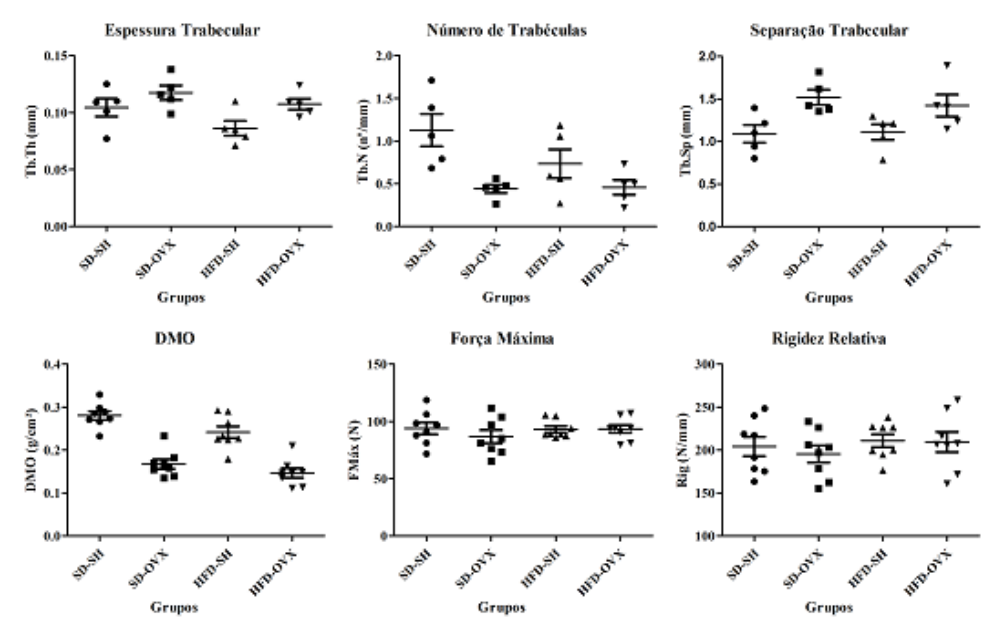

Figura 1. Resultados das análises ósseas obditas na Fase 2 do experimento

\section{DISCUSSÃO}

O objetivo desse trabalho foi estudar a relação entre a gordura e o osso utilizando uma dieta rica em gordura saturada em um modelo animal de ratas em crescimento e ovariectomizadas. Nossos resultados mostraram que durante o crescimento a dieta hiperlipídica não causa alterações microestruturais e mecânicas nos ossos, embora seja capaz de aumentar a DMO. Já tardiamente, após ovariectomia, a dieta hiperlipídica causa piora na qualidade microestrutural e DMO, mas não altera parâmetros mecânicos.

As dietas hiperlipídicas, caracterizadas por terem 35\% ou mais da energia na forma de gordura (Hariri e Thibault, 2010), têm sido usadas como modelos de indução à obesidade em diversos estudos experimentais (Riant et al., 2009; Halade et al., 2010; Fujita et al., 2016). A ingestão excessiva de lipídeos pode levar não só ao aumento da massa corporal e IMC (Jensen et al., 2016), mas também pode gerar alterações sistêmicas e comprometer a saúde óssea (Liang et al., 2010).

Primeiramente, o presente estudo avaliou ratas em crescimento para compreender os primeiros efeitos fisiológicos do consumo de gordura sobre os ossos. Esse estudo é relevante, considerando a alta epidemia de obesidade infantil, visto que as crianças são altamente atraídas pelo consumo inadequado de nutrientes (De Onis et al., 2010 ). Além disso, o efeito da obesidade no esqueleto, durante o crescimento, ainda não foi totalmente explicado e compreendido, pois embora um maior risco de fraturas em crianças obesas tenha sido relatado (Stagi et al., 2013), muitas vezes a DMO está aumentada nesses indivíduos. Uma vez que o consumo de dietas pode afetar a aquisição de massa óssea, o entendimento dessa relação precocemente é necessário, já que a aquisição insuficiente de massa óssea pode refletir em problemas osteometabólicos futuros (Morais e Burgos, 2007). Podemos observar que o efeito sistêmico da dieta hiperlipídica, além do aumento de massa corpórea, foi principalmente relacionado ao aumento da expressão do gene PPAR- $\gamma$ nas ratas em crescimento. Esse gene relaciona intimamente com a síntese de proteínas ligadas à adipogênese.

$\mathrm{Na}$ primeira fase do estudo, observamos que, embora a DMO tenha aumentado nas ratas alimentadas com dieta hiperlipídica, esse aumento não foi suficiente para melhorar a resistência mecânica. Isso pode ser explicado pela preservação da microarquitetura óssea. O número de trabéculas, a espessura trabecular e o espaçamento - parâmetros que determinam a qualidade óssea - foram semelhantes entre os dois grupos. Clinicamente, semelhante a algumas observações entre adultos, as crianças obesas podem apresentar maior DMO em comparação com crianças eutróficas, mas isso não significa que seus ossos sejam mais resistentes (Rendina-Ruedy et al., 2016).

Um segundo objetivo deste trabalho foi o de estudar os efeitos da dieta sobre os ossos de ratas ovariectomizadas, para avaliar a relação gordura versus osso sobre a influência também hormonal. Essa escolha é relevante, visto que tem sido evidenciado um aumento da adiposidade na medula óssea em mulheres pós-menopáusicas com osteoporose, 
mostrando uma negativa associação entre a adiposidade e taxa de formação óssea (Yeung et al., 2005; Blake et al., 2009; Shen et al., 2013).

Nossos achados mostraram que a cirurgia OVX aumento significativo da expressão de Catepsina-k. Esse gene está intimamente ligado à reabsorção óssea, uma vez que se relaciona com a síntese de proteínas que desempenham papel essencial na reabsorção do osso, degradante da matriz extracelular (Khajuria et al., 2011). Os efeitos locais que a cirurgia OVX exerceu nos ossos são consistentes com a literatura. As ratas castradas têm sido utilizadas como modelo experimental de perda óssea (Thompson et al., 1995). A OVX é capaz de diminuir a DMO, prejudicando a qualidade microestrutural do osso. Esses dados podem ser observados em nosso estudo, uma vez que a cirurgia OVX resultou em menores valores de massa óssea, DMO, número de trabéculas, enquanto que maiores valores de espaçamento trabecular e foram observados.

Ao contrário ao que foi observado nas ratas em crescimento, na segunda fase do experimento foi possível perceber uma diminuição significativa na DMO em resposta ao consumo de dieta hiperlipídica. Isso corrobora com a teoria atual de que o acúmulo de gordura corporal pode prejudicar a DMO durante a menopausa. Também foi observada uma diminuição na espessura trabecular em ratas alimentadas com a dieta hiperlipídica. Também foi observado que a dieta hiperlipídica, além de promover aumento da expressão relativa de PPAR- $\gamma$, o esperado neste estudo, causou uma diminuição na expressão de Runx-2, gene que se associa à síntese de proteína envolvida na formação de tecido ósseo (Lee et al., 2000).

Embora sejam necessários futuros estudos, os resultados aqui apresentados sugerem que, embora haja um aumento na DMO em resposta à HFD, não há influência na qualidade e função óssea em ratas em crescimento. Por outro lado, após a ovariectomia, a dieta hiperlipídica parece prejudicar o esqueleto, acentuando os efeitos negativos sobre a mineralização óssea causados pela deficiência estrogênica. Os resultados estão de acordo com Halade et al. (2010), que afirmam que animais mais velhos são mais susceptíveis aos efeitos da dieta hiperlipídica. Uma vez que as fraturas são ocorrências comuns em resposta à deficiência estrogênica, nosso estudo sugere que a alimentação rica em gordura pode representar um possível fator de risco para ocorrência de fraturas e problemas na recuperação das mesmas. Portanto, sugere-se estudos para melhor compreensão da relação entre fraturas, deficiência estrogênica e alimentação rica em gordura.

\section{REFERÊNCIAS}

BLAKE, G. M. et al. Effect of increasing vertebral marrow fat content on BMD measurement, T-Score status and fracture risk prediction by DXA. Bone, v. 44, n. 3, p. 495-501, 2009.

BLOOMFIELD, H. E. et al. Effects on Health Outcomes of a Mediterranean Diet With No Restriction on Fat Intake: A Systematic Review and Meta-analysis. Ann Intern Med, v. 165, n. 7, p. 491-500, 2016.

BOUXSEIN, M. L. et al. Guidelines for assessment of bone microstructure in rodents using micro-computed tomography. J Bone Miner Res, v. 25, n. 7, p. 1468-86, 2010.

DE ONIS, M.; BLÖSSNER, M.; BORGHI, E. Global prevalence and trends of overweight and obesity among preschool children. American Journal of Clinical Nutrition, v. 92, p. 1257-1264, 2010

FUJITA, Y. et al. Effect of dietary calcium deficiency and altered diet hardness on the jawbone growth: A micro-CT and bone histomorphometric study in rats. Arch Oral Biol, v. 72, p. 200-210, 2016.

GHANIZADEH, G. et al. The effect of supplementation of calcium, vitamin D, boron, and increased fluoride intake on bone mechanical properties and metabolic hormones in rat. Toxicol Ind Health, v. 30, n. 3, p. 211-7, 2014.

HALADE, G. V. et al. High fat diet-induced animal model of age-associated obesity and osteoporosis. J Nutr Biochem, v. 21, n. 12, p. 1162-9, 2010.

HARIRI, N.; THIBAULT, L. High-fat diet-induced obesity in animal models. Nutr Res Rev, v. 23, n. 2, p. 270-99, 2010.

HSU, Y. H. et al. Relation of body composition, fat mass, and serum lipids to osteoporotic fractures and bone mineral density in Chinese men and women. Am J Clin Nutr, v. 83, n. 1, p. 146-54, 2006.

JENSEN, B. A. H. et al. Dietary fat drives whole-body insulin resistance and promotes intestinal inflammation independent of body weight gain. Metabolism, v. 65, n. 12, p. 1706-1719, 2016.

KAFESHANI, O. et al. Major dietary patterns in Iranian adolescents: Isfahan Healthy Heart Program, Iran. ARYA Atheroscler, v. 11, n. Suppl 1, p. 61-8, 2015.

KAR, S.; KHANDELWAL, B. Fast foods and physical inactivity are risk factors for obesity and hypertension among adolescent school children in east district of Sikkim, India. J Nat Sci Biol Med, v. 6, n. 2, p. 356-9, 2015.

KHAJURIA, D. K.; RAZDAN, R.; MAHAPATRA, D. R. Medicamentos para o tratamento da osteoporose: revisão. Revista Brasileira de Reumatologia, v. 51, p. 372-382, 2011.

LEE, K. S. et al. Runx 2 is a common target of transforming growth factor beta1 and bone morphogenetic protein 2 , and cooperation between Runx2 and Smad5 induces osteoblast-specific gene expression in the pluripotent mesenchymal precursor cell line C2C12. Mol Cell Biol, v. 20, n. 23, p. 8783-92, 2000. 
LIANG, C.; DECOURCY, K.; PRATER, M. R. High-saturated-fat diet induces gestational diabetes and placental vasculopathy in C57BL/6 mice. Metabolism, v. 59, n. 7, p. 943-50, 2010.

LIM, S. et al. Body composition changes with age have gender-specific impacts on bone mineral density. Bone, v. 35 , n. 3, p. 792-8, 2004.

LIVAK, K. J.; SCHMITTGEN, T. D. Analysis of relative gene expression data using real-time quantitative PCR and the 2(-Delta Delta C(T)) Method. Methods, v. 25, n. 4, p. 402-8, 2001.

LOOKER, A. C.; FLEGAL, K. M.; MELTON, L. J., 3RD. Impact of increased overweight on the projected prevalence of osteoporosis in older women. Osteoporos Int, v. 18, n. 3, p. 307-13, Mar 2007.

MACEDO, A. P. et al. Influence of treadmill training on bone structure under osteometabolic alteration in rats subjected to high-fat diet. Scand J Med Sci Sports, Feb 2016.

MATKOVIC, V. et al. Timing of peak bone mass in Caucasian females and its implication for the prevention of osteoporosis. Inference from a cross-sectional model. J Clin Invest, v. 93, n. 2, p. 799-808, 1994.

MORAIS, G. Q.; BURGOS, M. G. P. D. A. Impacto dos nutrientes na saúde óssea: novas tendências. Revista Brasileira de Ortopedia, v. 42, p. 189-194, 2007.

PAULA, F.; ROSEN, C. Obesity, diabetes mellitus and last but not least, osteoporosis. Arq Bras Endocrinol Metabol, v. 54, n. 2, p. 150-157, 2010-03 2010.

PINHEIRO, M. M. et al. Nutrient intakes related to osteoporotic fractures in men and women--the Brazilian Osteoporosis Study (BRAZOS). Nutr J, v. 8, p. 6, 2009.

REEVES, P. G.; NIELSEN, F. H.; FAHEY, G. C., JR. AIN-93 purified diets for laboratory rodents: final report of the American Institute of Nutrition ad hoc writing committee on the reformulation of the AIN-76A rodent diet. J Nutr, v. 123, n. 11, p. 1939-51, 1993.

RENDINA-RUEDY, E. et al. Strain differences in the attenuation of bone accrual in a young growing mouse model of insulin resistance. J Bone Miner Metab, v. 34, n. 4, p. 380-94, 2016.

RIANT, E. et al. Estrogens protect against high-fat diet-induced insulin resistance and glucose intolerance in mice. Endocrinology, v. 150, n. 5, p. 2109-17, 2009.

SAHOO, K. et al. Childhood obesity: causes and consequences. Journal of Family Medicine and Primary Care, India, v. 4, n. 2, p. 187-192, 2015.

SHEN, C. L. et al. Energy-restricted diet benefits body composition but degrades bone integrity in middle-aged obese female rats. Nutr Res, v. 33, n. 8, p. 668-76, 2013.

SILVA, H. G. et al. Influence of obesity on bone density in postmenopausal women. Arq Bras Endocrinol Metabol, v. 51, n. 6, p. 943-9, 2007.

STAGI, S. et al. Bone metabolism in children and adolescents: main characteristics of the determinants of peak bone mass. Clin Cases Miner Bone Metab, v. 10, n. 3, p. 172-9, 2013.

THOMPSON, D. D. et al. FDA Guidelines and animal models for osteoporosis. Bone, v. 17, n. 4 Suppl, p. 125s-133s, 1995.

TINTUT, Y. et al. 8-Isoprostaglandin E2 enhances receptor-activated NFkappa B ligand (RANKL)-dependent osteoclastic potential of marrow hematopoietic precursors via the cAMP pathway. J Biol Chem, v. 277, n. 16, p. 14221-6, 2002.

YEUNG, D. K. et al. Osteoporosis is associated with increased marrow fat content and decreased marrow fat unsaturation: a proton MR spectroscopy study. J Magn Reson Imaging, v. 22, n. 2, p. 279-85, 2005.

ZHAO, R. et al. Combination of acupuncture with cupping increases life quality of patients of osteoporosis. Zhongguo Zhen Jiu, v. 28, n. 12, p. 873-5, 2008.

\section{AGRADECIMENTOS}

À Fundação de Amparo à Pesquisa do Estado de São Paulo (FAPESP: 2014/10733-8, 2014/25879-8, 2015/26142-1) e ao Fundo Europeu de Desenvolvimento Regional

\section{RESPONSABILIDADE PELAS INFORMAÇÕES}

Os autores são os únicos responsáveis pelas informações incluídas neste trabalho. 